\title{
EXPERIMENTAL STUDY OF ROCK TEXTURES ON SLOPE STABILITY
}

\author{
Mostafa Ahmed Ismail ${ }^{1}$, Tageldin Eltayeb ${ }^{2}$, Alaeldin Mohamed Elhassan ${ }^{2}$ \\ 1) Faculty of Petroleum and Mining Engineering, Suez Canal University, Egypt \\ 2) Faculty of Engineering, University of Khartoum, Sudan
}

\begin{abstract}
This article deals with the effect of rock textures on the slope stability in open cast mines and roads on mountains. Physical models were molded from Portland cement, quartz sand, basalt particles of different sizes in order to produce artificial rocks differ in their textures. Three kinds of rock textures where yielded; they are coarse, medium and fine textures. The bench height, berm and the angle of slope were also varied to study the effect of rock textures on the slope stability of open cast benches having coarse texture, grains larger than $5 \mathrm{~mm}$. It was found that the benches will only be stable when the height of bench is equal or less than 1.4times their berms and the slope angles should be less than 75 degree.

Failures will occur at slope angle near 90 degree as result of both tension and shear stresses. No failure would occur for rocks having fine texture, with medium texture rocks, the failure depends on the bench height.

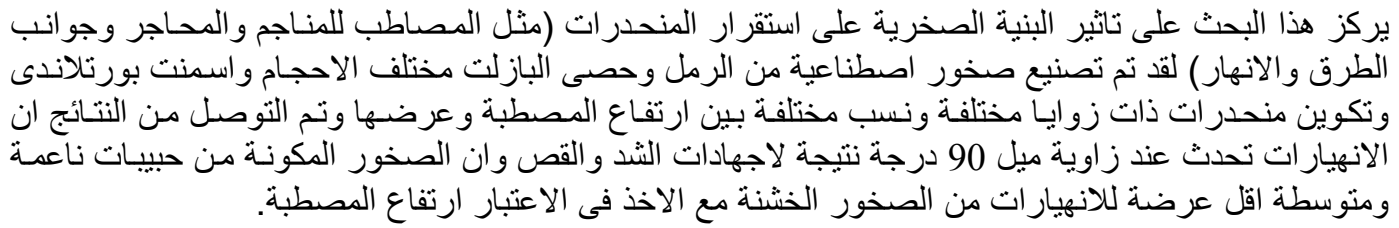

\section{INTRODUCTION}

In other sedimentary rock or mineral ores it is necessary to take in to account the relation between their structures, textures and the direction of cuttings.

In all cases of rocks or of mineral ores cuttings are rarely made with vertical walls and the sides of faces are generally sloped symmetrically at safe angle (9 and 10).

Open pit mines or quarries are large rock excavations that are usually intended mainly to strip away overburden materials from ores or rocks. Their designs, that is, the choice of the angle of stopes, widths of benches, and over all shape is now integrated with other mining cost factors to achieve maximum profit (11), too flat a slope will mean extra excavation and extra waste rock; but to steep a slope will increase the number of the lost time haulage road blockages and accidents.

Most of slopes of and open pit or quarry are temporary since the pit or quarry is ever enlarging simple instrumentation and quick response to sings of slope stability have allowed mining industries to work safely with slopes that will be judged too steep for civil engineering excavations of comparable size(12).
Movements of rock masses known as landslides, or landslips are caused by the direct or indirect action of gravity on un stable materials. They are important factors in the extraction of rocks or ore minerals from quarries and mines and frequently occur at stope phases or tunnel walls and road walls leading to the failure of quarries or mine benches or tunnel and road walls(1 to 5).

landslides may be divided in to tow groups according to the nature of movement involved (4,6 and 7) .

a) slides, in which a surface of slides is present, separating the moving mass from the stable ground.

b) flows, in which there is no surface sliding but movement takes place by continues deformation;(1 and 4).

In open casts or quarries excavation the nature of the rock and mineral ores through which excavation is made will govern questions of construction such as the slope of benches or the slides of tunnels or the slope of hills, method and rate of excavation and to a great extent its $\operatorname{cost}(1$ and 4$)$. Thus, vertical sides are possible in massive bedded hard strata, horizontal or gently dipping, with few joints, ore in strong igneous rocks. 
In soft rocks and ores, like shales, hydrothermally altered zones, and deeply weathered granites, design of safe slopes in an extension of soil mechanics theory, since such materials tend to fail by slumping or sliding through the body of rock itself, (1).

In most hard rocks and in some of softer rocks as well, preexisting discontinuities control the avenues of rock movement so modes of slope failure occur that are not usual in soils. Special methods for analyzing these structurally controlled failure modes have been devised by workers in rocks mechanics, (4).

The effects of kind of rocks the water content, the structural geology, the bench design parameters such as height of benches and their widths, specific gravity of rocks, etc .were studied by many workers in rock mechanics as well, $(4,13$ and 14$)$.

It is believed that the texture and the characteristics of grains of minerals of rocks would play significant roles on the slope stability during extraction of rocks from their deposits. Hence, physical models were made of cement, sands having small amounts of iron oxides, water and basalt particles. The basalt particles used of three sizes that is small, medium and large particles, in order to study the effect of rock grain sizes on the slope stability. Also, the effects of the height of the benches and their slopes on the stability of these benches were studied, and the results are present in this article. The modes of failure for each case are shown.

\section{EXPERIMENTAL WORK}

\subsection{Materials}

(I) Cement, silica sands, water and particles of basalt rock were employed to make the models which are similar to the open cast or quarries benches.

(II) The used cement was Portland cement (OPC). (III) Silica sand having size range from $0.295 \mathrm{~mm}$ to $0.104 \mathrm{~mm}$ was washed to remove all clay materials and dirt from it.

(IV) Drinking tap water was used for molding the models.

(V) Basalt particles were screened to give three groups of average sizes. They were 13.33, 6.68 and $3.33 \mathrm{~mm}$, (see Plate 1).

It is worth to mention that cubes made of the sand, water and cement mortar and tested under uniaxial compressive machine to determine the strength of the matrix of the artificial rock. The strength of the basalt rock was also determined. They were 240 and $1000 \mathrm{~kg} / \mathrm{cm} 2$ respectively. These obtained results were used to discuss and analyze the results of bench models.
Models of these materials were treated to produce benches having different heights and different slope angles as shown in Plate 2. The heights were selected

to be 1.4 and 2 times of the bench berm. The angles of slope were 90؛75 ؛ and 60؛, which are usually found in practice.

\subsection{Testing Procedure}

(i) Uniaxial compression machine was used which is computerized to give slow loading rate to simulate the static load resulted from the rock weights of benches.

(ii) The models were tested while they were confined from three sides to be similar to the benches at quarries and open cast mines.

\section{PRESENTATION AND DISCUSSION OF THE RESULTS}

The results of the present work are shown in Figs. 1 to 4 . Fig. 1 shows the effect of grain sizes of the rock on the failure loads for different slope angles where bench height is twice the bench berm. It could be read out from the curves on this figure that the rocks which will contain fine agglomerates (grains) will have a higher resistance to slide, than those containing medium and large grains. The increase in the value of angle of slope also would decrease the resistance of rock sliding for all agglomerate sizes. The rate of decreasing is much lower for the fine agglomerates than both medium and large agglomerates. The relationships between the failure load which represents the weight of the bench and the angles of slope take straight lines for all sizes of agglomerates.

Figure 2 shows the relationship between the failure loads of benches and the grain sizes (agglomerate sizes) of the rock. The results have the same trends of the above summarized results, i.e., the rock resistance to failure by sliding decreases with increasing both the angle of slope and the sizes of agglomerates, However, the relationships took second order equations which are shown by the curves.

Figures 3 and 4, show the relations between the failure loads and both angles of slope and sizes of rock agglomerates, when the highs of benches were 1.4 times their berms instead of 2 times. The relations indicate the same trends as before, but all relations are seen as second order relations, (giving curves), for the angles of slope and for the sizes of rock agglomerates. However, it is surprising that the failure resistances of rock to slide were decreased by a factor of $16.5 \%$ when the bench height to the berm of the bench was decreased by a factor of $30 \%$. Explanations which could be given here for the above described results are the fine texture rocks, where the gains will have larger surface area than 
both medium and coarse textures, therefore, the cohesion between the grains and the cementing materials will be greater for fine grains than that between the cementing materials and medium and coarse grains, Hence the resistance to failure is greater for fine grains that for both medium and coarse ones.

In addition, the shapes of coarse and medium grains are shown to take flake shapes, while the shape of fine grains is nearly cubic referring to rock mechanics principles, rocks having course and flake shape grains will have a low resistance to breaking than that composed of fine grains. This explains the given results.

Plate 2 and 3 shows the failure modes for the different sizes and different angles of slopes

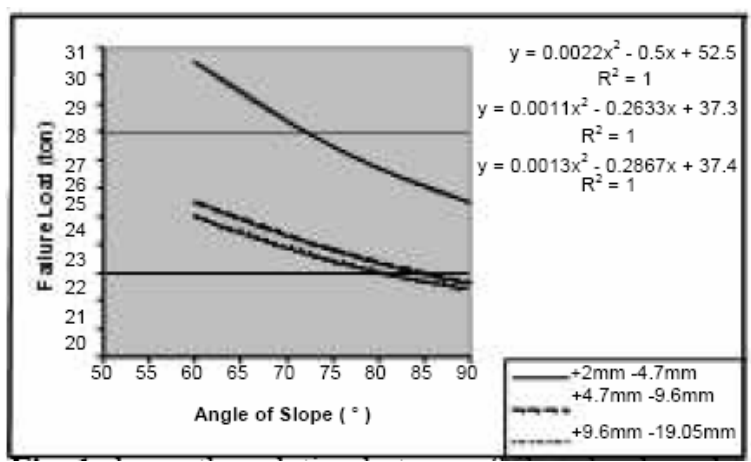

Fig. 1 shows the relation between failure loads and angle of slope for different grain sizes, bench height 2 times the bench width

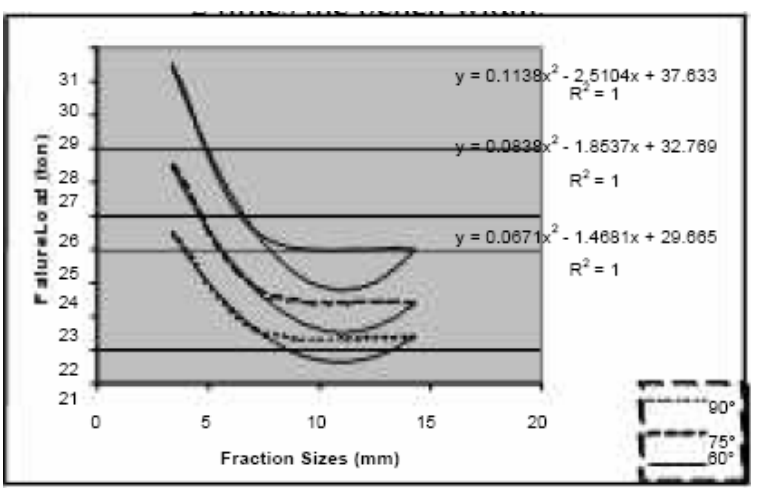

Fig. 2 shows the relationship between failure loads and grain sizes for different angles of slope, bench height 2 times the width of bench

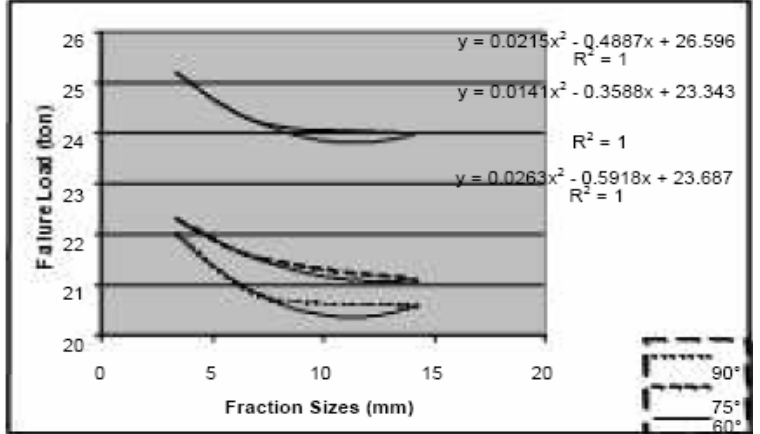

Fig. 3 shows the relationship between failure loads and grain sizes for different angles of slope, bench height 1.4 times the width of bench

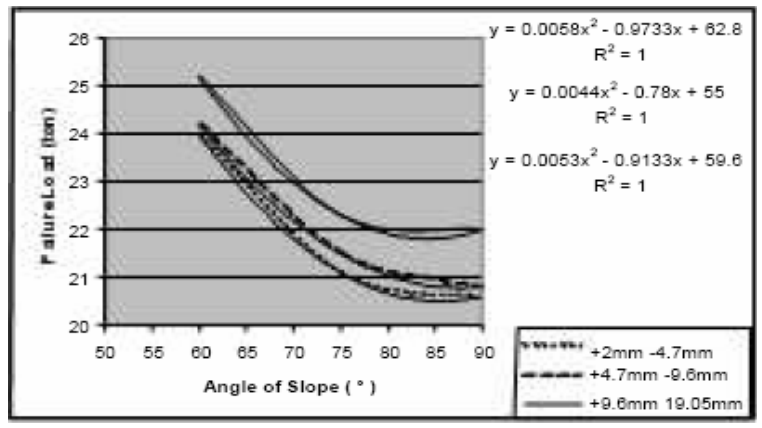

Fig. 4 shows the relationship between failure loads and grain sizes for different angles of slope, bench height 1.4 times the width of bench
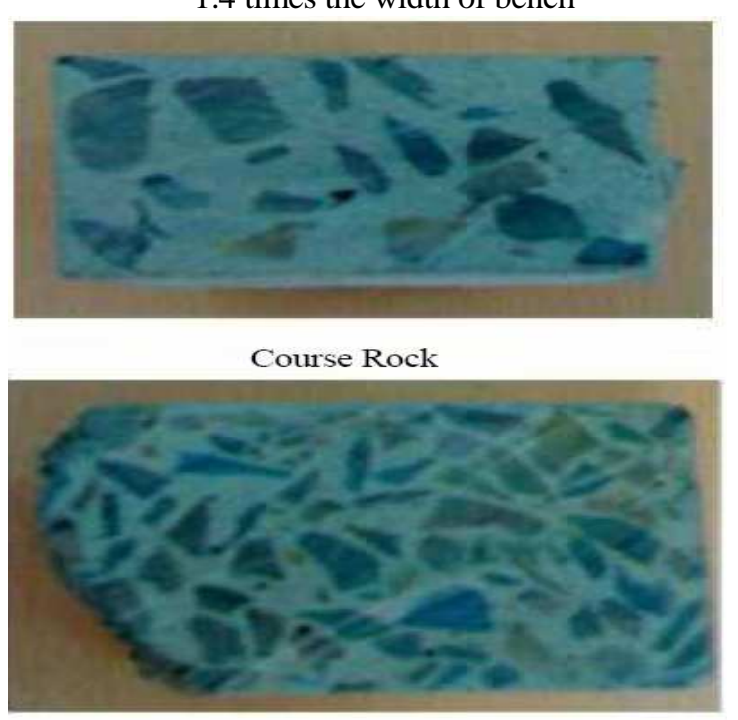

Medium Rock

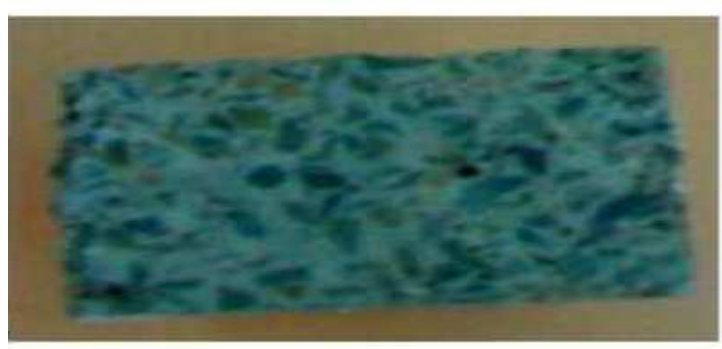

Fine Rock

Plate (1) 
Mostafa Ahmed Ismail, Tageldin Eltayeb, Alaeldin Mohamed Elhassan, "Experimental Study of Rock ..."

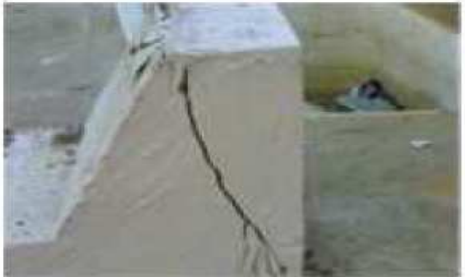

Course 60

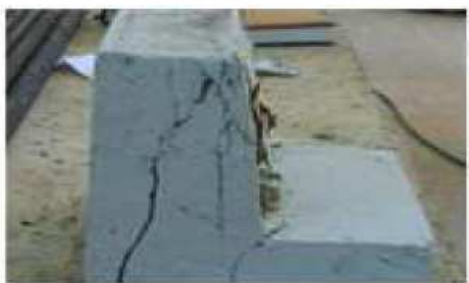

Course 75

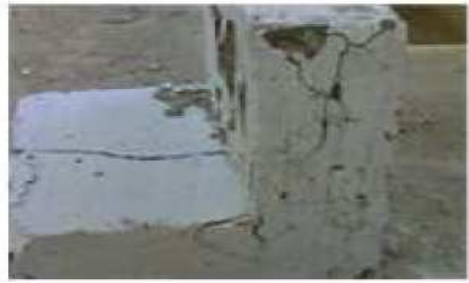

Course 90

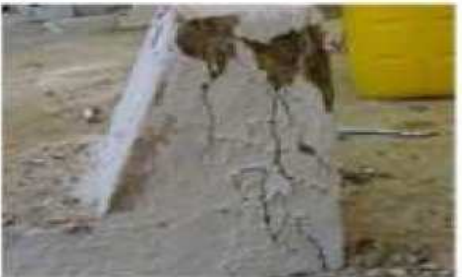

Medium 60

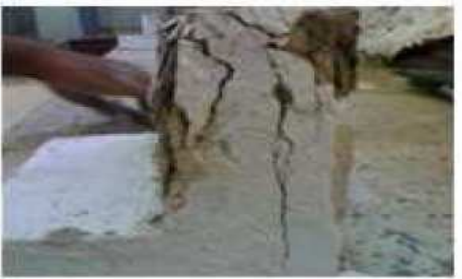

Medium 75

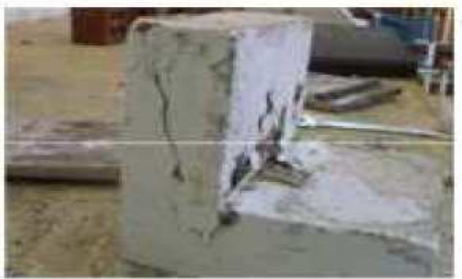

Medium 90

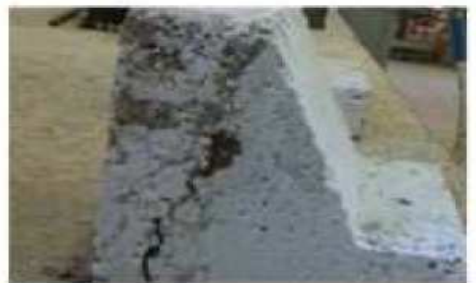

Fine 60

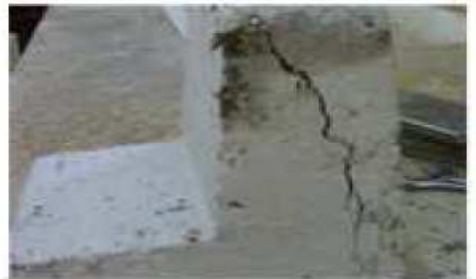

Fine 75

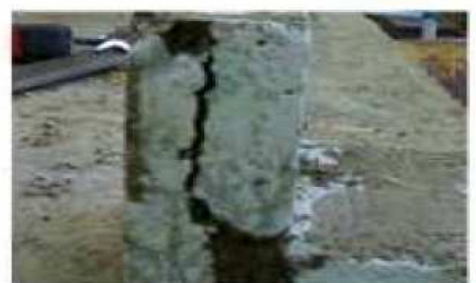

Fine90

Plate (2) Height of bench equals the width of berm

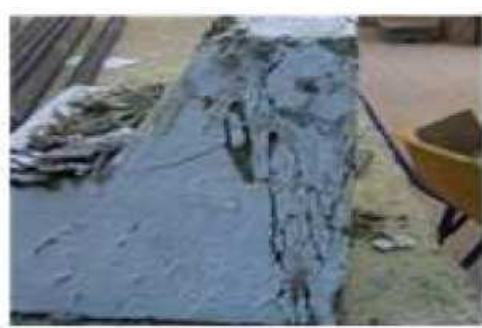

Course 60

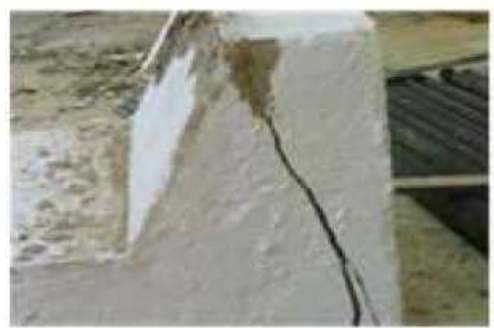

Course 75

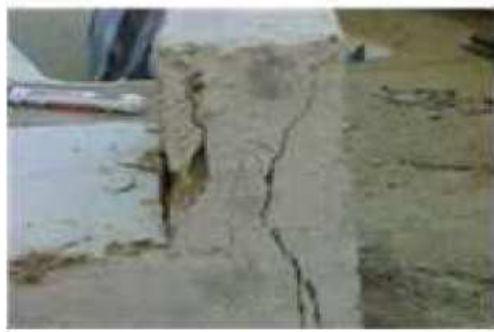

Course 90

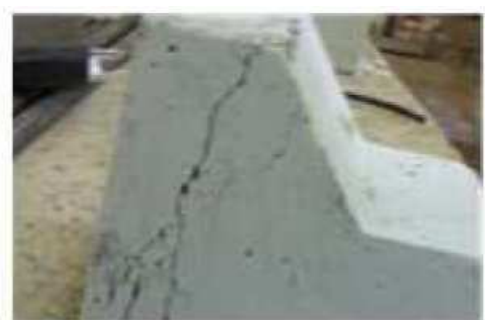

Medium 60

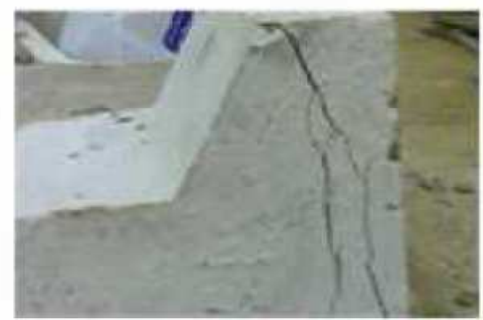

Medium 75

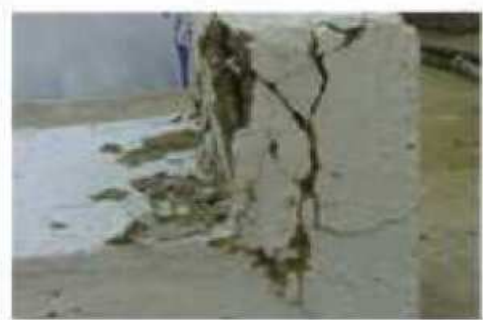

Medium 90

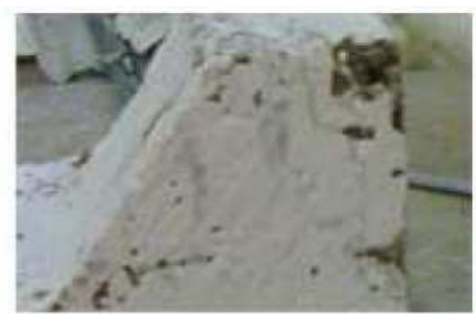

Fine 60

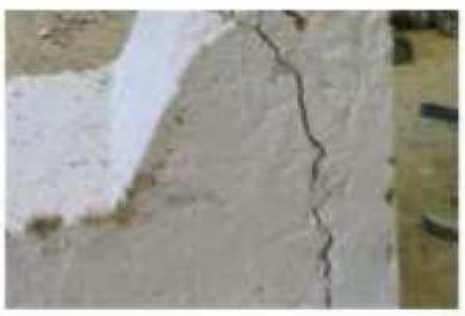

Fine 75

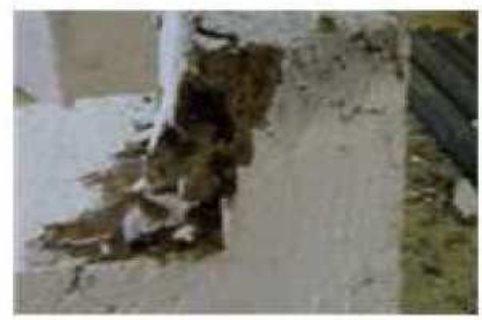

Fine 90

Plate (3) Height of bench 1.4 the width of berm 


\section{CONCLUSIONS}

It could be concluded that rocks such as volcanic tuffs which are layers of consolidated ash and dust which become hardened into rocks for some distance around the volcano and are known as agglomerate when these rocks are quarried or extracted from the surface, the angle of bench slope and the height of the bench will of course, be dependent on the sizes of the agglomerates embedded in these consolidated ash and dust layers, i.e. rocks composed of fine grains (fine agglomerates) will have a great resistance to failure than those of coarse agglomerates and the angle of slope of benches for fine agglomerates. Benches will be more stable even at higher slopes, if they are of fine grained rocks. Also, they may be easier related to drilling operation.

\section{APOLOGY}

Mostafa Ahmed Ismail apologizes for his colleagues due to the disappearing their names from the paper published on April issue 2009.

\section{REFERENCES}

[1] Selby, M,J, (1982) , Hill slope material and processes, Oxford University press, Oxford, pp.118-185.

[2] Bjerrum, L., (1967), Progressive failure in slopes of overconsolidated plastic clay and clay shales J.S.M.F.E.D., American society of civil engineers, 93, pp.1-11.

[3] Patton, F.D and Deere, D. U.,( 1970) Geologic factors controlling slope stability in open cast mines, first International conference on stability in open pit mining, Canada.
[4] Goodman, R.E.,( 1980) Introduction to rock mechanics. John Willey and Sons New York.

[5] Heok, E.V., (1970) Influence of rock structure on stability of rock slopes ,first International conference on stability in open pit mining, Canada.

[6] Black, R.A.L. and Jenning, J.E.,(1963) Factors affecting the angle of slope in open cast mines, SME of AIME .

[7] Hoek, E. and Pentz, D.L., (1970) Review of the role of rock mechanics in the design of open cast mines, 9th Commonwealth mining and metallurgical congress, London

[8] Hoek, E. and Sharp, J.C.,(1970) Improving the stability of rock slopes by drainage open pit mines, Mining Symposium, Johannesburg.

[9] Hoek E., (1970) Influence of rock structure on the stability of rock slopes, first International conference on stability in open pit mining, Canada.

[10] Winder, C. R. and Thompson, A. G., (1993) SFEX stability assessment for excavations in rock. Rock Technology Software, Australia.

[11] Rezhevsky .V. V., (1985) Open Cast Mining unit Operations translated from Russian Mir Publication, Moscow.

[12] Wyllie, D.C. and Mah, ch. W., (2001) Rock Slope Engineering, Spon Press, London.

[13] Terlien, M.T.J., (1998) The Determination of Statistical and Deterministic Hydrological Landslide Triggering Thresholds, Geotech.

[14] Alan. B, and Peter. N.C., (1971) The Influence and Evaluation of Blasting on Stability, first International conference on stability in open pit mining, Canada 